\title{
Teacher-employed Communication Strategies: Investigating Function Type Occurrence in Iranian EFL Context
}

\author{
Massoud Yaghoubi-Notash (Corresponding author) \\ English Department, Faculty of Persian Literature \& Foreign Languages \\ University of Tabriz, Tabriz, Iran \\ Mohammad Amin Karafkan \\ English Department, Faculty of Persian Literature \& Foreign Languages \\ University of Tabriz, Tabriz, Iran
}

Received: 12-07-2014

doi:10.7575/aiac.ijalel.v.4n.2p.73
Accepted: 30-09-2014

Published: 01-03-2015

\begin{abstract}
Communication strategies, as goal-oriented lines of action to obviate breakdowns in the flow of communication, have been the subject of extensive studies in SLA. While student-employed strategies have been duly investigated in the literature, those employed by teachers in the classroom context continue to be inadequately addressed. Moreover, characterizing functions of communication strategies (CSs) rather than their types as a research interest can offer new insights for research. Accordingly, the present study concentrated on the function of CSs employed by 16 teachers across elementary (8) and advanced levels (8) teaching spoken English in private institutes in Tabriz, Iran. A modified version of Jamshidnejad's (2011) functions of communication strategies was employed as the framework for defining functions. T-test results indicated a significant difference regarding 'maintaining the flow of conversation' between elementary and advanced level teachers. As with other function types, no significant differences could be revealed.
\end{abstract}

Keywords: communication strategies, teacher-employed strategies, strategy functions

\section{Introduction}

When struggling to communicate the meaning, non-native and native speakers of any language try sometimes to find a suitable grammatical construction or expression that, for some reason or other, cannot be cognitively accessed and verbalized. Such a failure or slip-of the-mind is because individual linguistic repertoire is obviously not a perfect system. In fact, there is a gap between the intention of individual to communicate and the immediately available linguistic repertoire. In order to manage and fill these gaps, goal-oriented lines of action are employed which are known as communication strategies (see Maleki, 2007). In other words, these strategies are, in effect, steps taken by language speakers in order to promote the effectiveness of their communication (Littlemore, 2003).

\subsection{Communication strategies: Definitions and Classifications}

The term communication strategies was first coined by Selinker in 1972 in theorizing 'interlanguage' (see Dong, 2010). Later, contrastive approaches to the definition of communication strategies distinguished "interactional" (Tarone, 1980, and "psycholinguistic" (Faerch \& Kasper, 1983). Tarone (1981) argued that communication strategies are "mutual attempts of two interlocutors to agree on a meaning in situation where the requisite meaning structures do not seem to be shared" (p. 220). On the other hand, Faerch and Kasper's "psycholinguistic" definition suggests that communication strategies address the speaker's experience of communicative problems and the solutions they follow whether these solutions are cooperative or non-cooperative (Abunawas, 2012). Thus, following Faerch and Kasper (ibid), communication strategies are "potentially conscious plans for solving what to an individual presents itself as a problem in reaching a particular communicative goal" (p.36) (see Also Ellis, 1986). In this way, communication strategies (CSs) are viewed within a general model of speech production where 'individuals' rather than 'learners' are held to employ strategies, which in turn implies CS occurrence in L1 as well (Abunawas, 2012).

Dornyei and Scott (1995) extended the scope of communication strategy. They argued that "every potentially intentional attempt to cope with any language-related problem of which the speaker is aware during the cause of communication" can be called a strategy. However, Canale (1983) goes further and argued that CSs include any strategy or plan of action that "enhances the effectiveness of communication" (p.11 see also Omar et al, 2012).

\subsection{Different Classifications of Communication Strategies}

Disparity of definitions makes it difficult to come up with a universal framework. Numerous classifications have been suggested by Tarone (1981), Faerch \& Kasper (1983), and Bialystok (1990), etc. However, almost all the classification systems tend to group CSs into the following categories: 

a) communication strategies based on successful language learners' “ performance (O’Malley, 1990);
b) communication strategies based on language functions (Tarone, 1981);
c) communication strategies related to native language and L2 language (Bialystok, 1990);
d) communication strategies based on communication goals and means (Pariakht, 1985); and
e) Faerch \& Kasper's (1983) classification from psycholinguistics' perspective.

The classifications above indicate a lack of coherence in the related literature and a want of a well-accepted comprehensive system for describing and defining these strategies (Dong, 2010). However, a majority of the primary earlier classification of CSs in the literature has been integrated by Dornyei \& Scott (1997). Their taxonomy is based on the manner of problem management in their extended taxonomy of problem-solving strategies. Three basic proposed categories of communication strategies are: direct, indirect and interactional strategies.

Direct strategies are defined as alternative, manageable and self-contained means of getting the (sometimes modified) meaning across. For example direct strategies like circumlocution or approximation are employed in order to compensate for a lexical gap. On the other hand, indirect strategies, facilitate meaning conveyance to take place indirectly by providing the conditions for achieving mutual understanding (e.g. the use of fillers and repetitions for preventing breakdowns and keeping the communication channel open). Interactional strategies include cooperative trouble-shooting exchanges which involve appeal for help and request for clarification (Dornyei \& Scott 1997)

\subsection{Findings on CSS}

Various studies have touched up the different aspects of CSs over the last decades. These studies include using and instructing them. Several researchers have investigated recently, the communication strategies used by Chinese EFL learners. For example, Huang and Naerssen (1987) and Chen (1990 as cited in Teng, 2012) investigated the communication strategies used by EFL learners in China. Jackson (2002) examined the restraints of EFL students in Hong Kong in their case discussions. Some studies have also been done with EFL students in Taiwan. For instance, Liao and Bresnahan (1996) designed a contrastive study of refusal strategies between Mandarin Chinese and American English. Hsieh (1998) investigated the relationship between the use of communication strategies and anxiety. Tuan (2001) examined the relationship between the choice of communication strategies and extroversion-introversion tendency. Zhang (2005) also examined the use of communication strategy in dyad talks and the function of proficiency level in strategy selection. Moreover, there have been some studies which examined on the field of teaching communication strategies to L2 learners. For example, Willems (1987) proposed some practice in the use of L2 communication in L2 classroom. One of the main purposes of communication strategy instruction, based on Rost (1996 as cited in Teng, 2012) study, is to help learners guess the conversation management problems and to help them deal with these problems. Ya-ni (2007) gave some suggestions of training communication strategies, creating an English-speaking environment as well as officially highlighting communicative competence. The findings of Lam (2010) indicated that strategy instruction might affect low-proficiency students more than high-proficiency students in terms of both strategy use and task performance. Furthermore, Ogane (1998) suggested the guidelines for teaching five mostly-used communication strategies (paraphrasing, borrowing from L1, miming, asking for help, avoiding) along with classroom techniques and specific exercises. According to Yule and Tarone (1997), the definitive study on the value of communication strategy teaching remains to be done. Moreover, Faucette (2001) came in to conclusion that communication strategy has been evaluated from the pedagogical perspective by very few studies. Tarone and Yule (1987) also investigated the communication strategies of second language learners by using Task-based methodology. The subjects were 24 Asian and South American learners and nine native speakers of English. In that study, there were two learners in each session. One described an object while the hearer tried to figure out that object; the two learners then exchanged roles. The same procedure was followed to gather information from the nine native speakers. There were two other tasks that were given to the two groups: to give instructions for the assembly of an apparatus and to narrate a story reporting actions taking place in a classroom scene. The strategies employed by the non-native speakers were circumlocution (giving description), appeal, literal translation, mime, and message abandonment. Native speakers resorted more to circumlocution and approximation than did non-native speakers. Also non-native speakers gave more details in their description than native speakers did who felt that extra details were not necessary. Wood (2011) found out that implementation of communication strategies into classrooms can improve student's productivity while continually building on the foundations of CLT. Jamshidnejad (2011) investigated that how a group of language learners develop the accuracy level of their target language in oral communication when they encounter the problem and found out that communication strategy usage in L2 interpersonal communications enables participants to promote accuracy level of their target language. Mei (2010) conducted a research on the use of communication strategies by Chinese EFL learners and his findings demonstrated that students' use of communication strategies was influenced by three variables: task type, English proficiency level, and academic major. Chen (1990) and Tarone and Yule (1989) mentioned that some researchers have shown the way the native speakers have solved the problem occurring in communication by some communication strategies and Applegate (1980) confirmed the use of communication strategies by native speakers and teachers as higher proficient interlocutors.

\subsection{Non-native teachers' communication strategies}

Teacher training programs might be inadequate when these programs don't take in to account teachers' oral instructional language needs particularly where the second language is the medium of instruction. This is due to the fact that 
language is required in order to reformulate thought processes (Vygotsky, 1978 as cited in Azian , Raof, Ismail, \& Hamzah, 2013), allowing meaning to be conveyed and created (Marton and Tsui, 2004). Communication which takes place in a pedagogic context particularly in the form of teachers' oral language is at the center of teaching and learning. In English language teacher education, novice teachers should have knowledge about the language, and proficiency in the language (Davies, 2002). In effect, Marinova-Todd, Marshall, \& Snow (2000) proposed that the success of students' language education relies on well-trained teachers who are native or native-like speakers. Being native or native-like has the implication of having native speakers' communicative competence. Alptekin (2002) stated that training nonnative speakers to access native like communicative competence might not be attainable. Strategic competence including communication strategies among the four communicative competence components, is absolutely necessary to be incorporated into non native teachers' L2 language training. Hoekje and Williams (1992) argued that although the use of communication strategies may not enhance non-native speaker teachers' linguistic competence, "there may be gains in teaching effectiveness".

Todd (2005) studied teachers' use of repetitions, particularly self-repetitions, and according to his results the repetitions were mainly used for the aim of re-initiation, emphasis, affirmation, clarification and left-fronting. This came to conclude that teachers use repetitions mainly in order to help students' comprehension. Viano and Conejos (1996) were in line with Todd (2005) and they also concluded that in order to transfer information more efficiently, teachers use either verbatim or rephrased self-repetitions. Cullen (2002) mentions that teachers' reformulation of student responses and echo can help strengthen pedagogic aims. Chin (2006) shows how teachers enhance students' existing knowledge by requesting further clarification of students' pervious contribution. Similarly, Nassaji and Wells (2000) showed that the strategy of teachers requesting further clarification of students' responses may create support for students' learning to occur. This is because clarification request which enhances an extended discussion (Nassaji and Wells, 2000). Confirmation checks as another type of communication strategy has been used by teachers in order to promote student comprehension (Azian et al, 2013). Ustunel and Seedhouse (2005) argued that teachers used code-switching to check student comprehension, encourage students to participate and control the classroom. Moreover, Martin (1999) believes that code-switching helps to clarify the meaning of certain portions of written texts, and Ferguson (2003) argues that this type of communication strategy may create amity between teachers and students. Eventually, some special communication strategies of teachers in classroom discourse affect students' understanding.

Having reviewed the literature on strategies and the outcomes of their employment, the present research seeks to establish whether there are any significant differences used by EFL teachers in Advanced and Elementary level classrooms regarding strategy functions in the context of private language institutes as communication-based EFL instruction contexts.

\section{Methodology}

\subsection{Participants}

The researchers focused on 16 teachers, 8 of whom were teaching elementary-level spoken English courses and the remaining 8 teaching advanced-level spoken-English courses in six private language institutes in Tabriz, Eastern Azarbaijan province, at the northwest of Iran. Therefore, participants included 16 EFL teachers aged between 23 to 26 teaching 132 students. The focus on teachers as strategy employers did not mean excluding the learners; in fact, the study could be argued to have concentrated upon the classroom discourse going on among the learners and the teachers. The teachers were both experienced and academically-educated in TEFL.

\subsection{Procedures}

The researchers used IC-recorder to record the entire classroom discourse between teachers and students. Note papers had been prepared to jot down and note some specific information like the number of the participants, the number of the sessions and the number of written words on the classroom blackboard or whiteboard or teacher-initiated dictionary use as a strategy type. It was impossible for the researchers to video record the class due to local policies in the institutes.

Altogether, 85 hours and 33 minutes of all classroom discourse between the teachers and learners, that is, 43 hours and 3 minutes from each level were recorded. The participating teachers were initially briefed up on the overall framework, but the objective was not disclosed to them since it might have influenced their performance. Data transcription was adapted from Van Lier (1988).

A modified version of Jamshidnejad's (2011) functions of communication strategies was employed. Additionally, a newly found function called acknowledgement and refusals was included to accommodate strategy functions. To ascertain the right designation of the strategy, the researchers orally cross-checked the teachers' responses who explicated their purposes of the specific strategies they used. The study adopted Bygate's (2000 as cited in Sumsai, 2011) definition of communication strategies. Bygate (2000) argued that communication strategies were used not only to face any language-related problems of which the speaker was aware during the course of communication, but also to enhance the effectiveness of communication even if there was not any problem or difficulty in an oral communication. By this definition the researchers also added communication enhancement as a function in using communication strategies to his model. The modified functions and communication strategies are as follows in Table 1. 
Promoting meaning transfer \& communication enhancement

\begin{tabular}{|c|}
\hline Description \\
\hline Example sentences \\
\hline Demonstration \\
\hline Antonymy \\
\hline Synonymy \\
\hline Omission \\
\hline Writing or spelling words \\
\hline Use of all similar sounding words \\
\hline Use of all purpose words \\
\hline Literal translation \\
\hline Code switch \\
\hline Asking for clarification \\
\hline Asking for confirmation \\
\hline Asking for repetition \\
\hline Comprehension check \\
\hline Interpretive summary \\
\hline Guessing \\
\hline Expressing non-understanding \\
\hline Appeal for help for meaning negotiation \\
\hline Topic avoidance \\
\hline Message abandonment \\
\hline Message replacement \\
\hline Self repair \\
\hline Other repair \\
\hline Restructuring \\
\hline Verbal strategy marker \\
\hline Retrieval \\
\hline Appeal to dictionary \\
\hline Use of fillers \\
\hline Self repetition \\
\hline Confirmation \\
\hline Rejection \\
\hline Other repetition \\
\hline
\end{tabular}

Promoting accuracy of language in communication*

* Monitoring, Improving and warning about the accuracy level of performance

** collaborating to continue and use of fillers and repetition (Chen, 1990)

\section{Data Analysis}

It is evident that the function of promoting meaning transfer and comprehension enhancement is used more in the two groups and the function of promoting the accuracy is the least used function among the functions of communication strategies in two groups. The researcher used independent-samples t-test in order to compare the results of two groups that are independent of each other. Because the observations and sampling from the two groups of teachers were completely independent, and since the ratio was calculated for strategy occurrence, independent samples t-test was used for significant differences. Following Table (2), it can be seen that the mean of frequency in using the function maintaining the flow of conversation in elementary level by teachers equals to 138.12 with standard deviation of 52.75 and the mean and standard deviation of using this function in advanced level by teachers are 247 and 106.13 respectively. Therefore, based on the $t$ of 2.598 was demonstrated to be significance level of 0.021 , it can be concludedthat difference of frequency ratios in using this function between the two groups is significant because the significant level is lower than 0.05 and this function is used more in advanced level.

Table 2. Descriptive data on functions of strategies employed by teachers at elementary and advanced levels

\begin{tabular}{lccccc}
\hline Strategy Function & Group & $\mathrm{N}$ & Mean & St. Deviation & St. Error of Mean \\
\hline PMTCE $^{1}$ & Elementary & 8 & 472.75 & 144.28 & 51.01 \\
& Advanced & 8 & 562.37 & 275.01 & 97.23 \\
PAIC $^{2}$ & Elementary & 8 & 96.25 & 43.47 & 15.36 \\
& Advanced & 8 & 125 & 67.12 & 23.72 \\
MFC $^{3}$ & Elementary & 8 & 138.12 & 52.75 & 18.65 \\
& Advanced & 8 & 247 & 106.13 & 37.52 \\
$\mathrm{~A} ~ \& ~ R^{4}$ & Elementary & 8 & 381.37 & 112.28 & 39.69 \\
& Advanced & 8 & 343.87 & 155.70 & 55.05 \\
\hline
\end{tabular}

\footnotetext{
promoting meaning transfer and comprehension enhancement

2 promoting accuracy of language in communication

${ }^{3}$ maintaining the flow of conversation

${ }^{4}$ acknowledgements and refusals
} 
Table 3. T-test results comparing mean frequency of function types at elementary and advanced levels

\begin{tabular}{lccc}
\hline & t-value & $\mathrm{d} f$ & Significance \\
\hline PMTCE & -0.82 & 14 & 0.43 \\
PAIC & -1.17 & 14 & 0.33 \\
MFC & -2.60 & 14 & $0.02^{*}$ \\
A \& R & -0.553 & 14 & 0.59 \\
\hline
\end{tabular}

* significant at $\mathrm{p}<0.05$

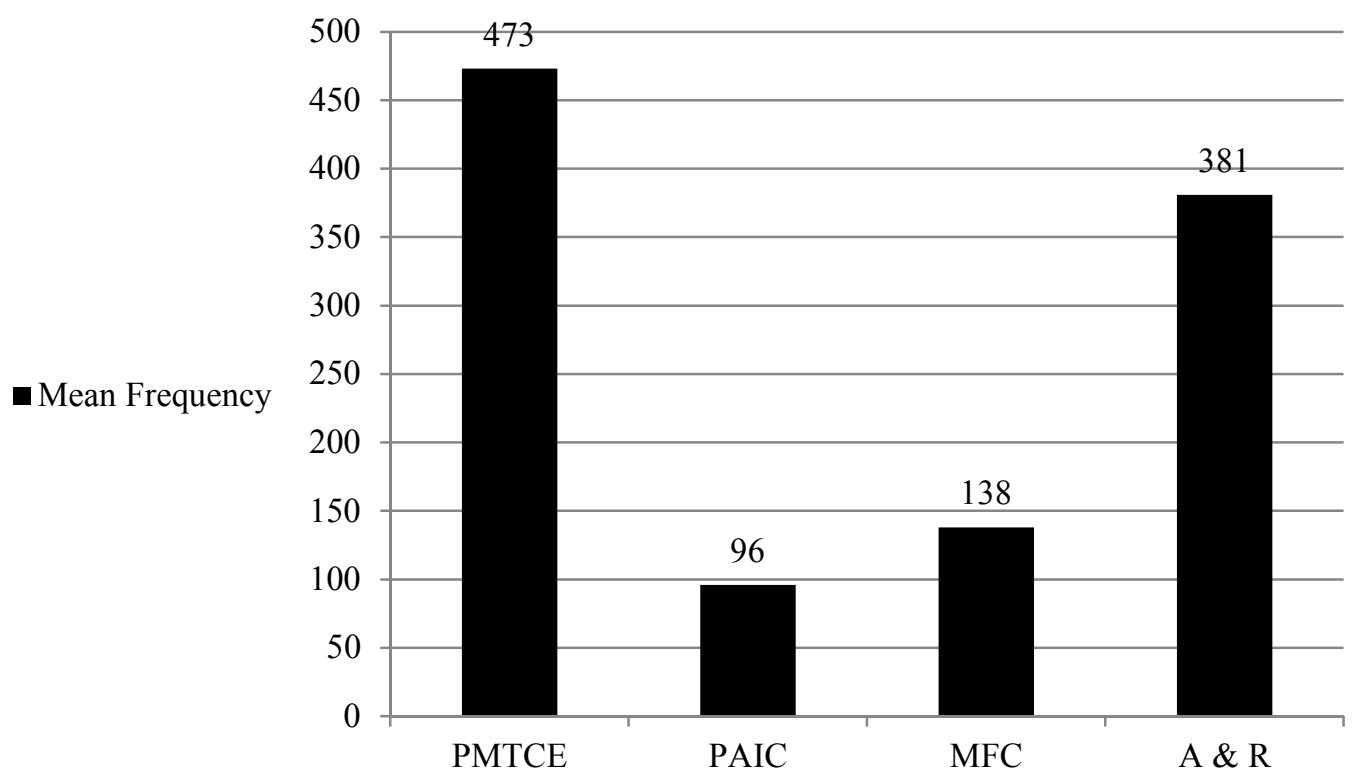

Figure 1. Mean frequency of strategy function types employed by teachers teaching elementary levels

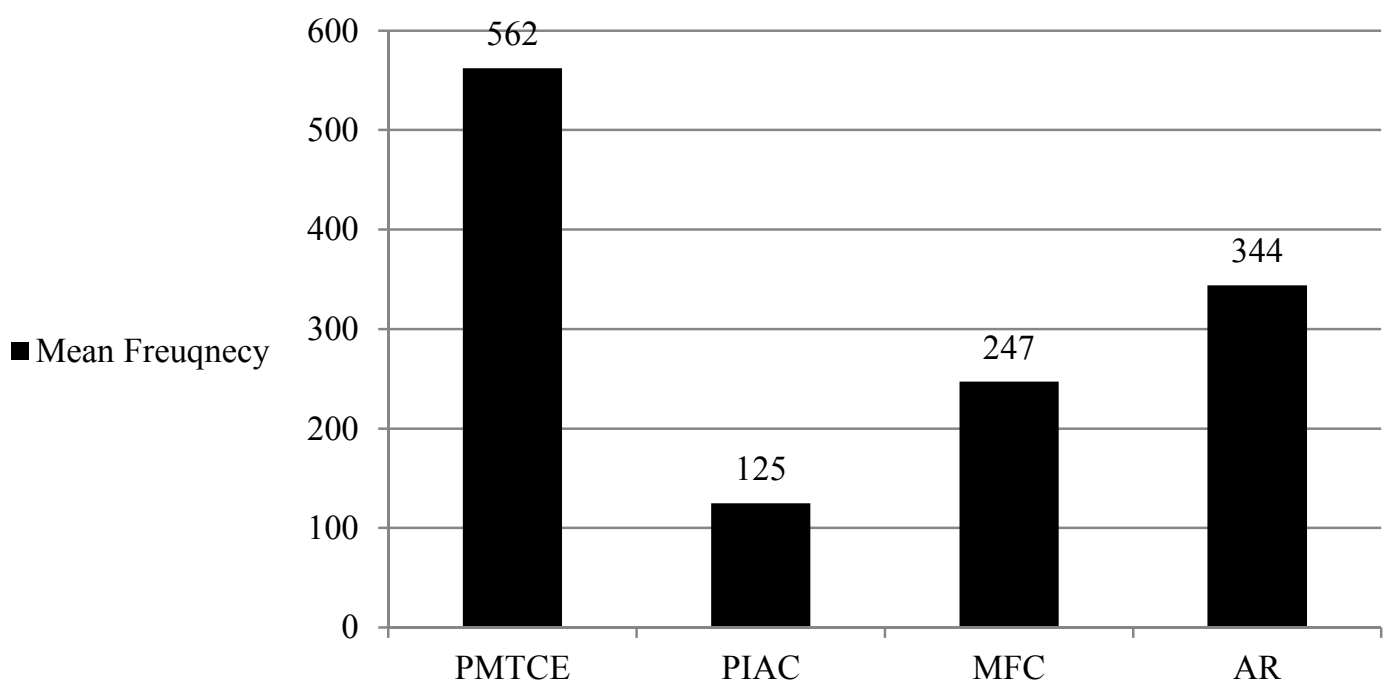

Figure 2. Mean frequency of strategy function types employed by teachers teaching advanced levels

\section{Discussion \& Conclusion}

To investigate whether there are any differences in functions of communication strategies used by EFL teachers in advanced vs. elementary level classrooms in private language institutes, the study adapted Jamshidnejad's (2011) model of the functions of communication strategies while adding two other functions, namely, refusals and acknowledgment and comprehension enhancement. Statistical analysis of collected data indicated that there is a significant difference in employing 'maintaining the flow of conversation' between the teachers who teach at elementary levels and those teaching at advanced level. In using other functions of communication strategies no significant difference could be demonstrated in this study.

Following Jamshidnejad (2011), participants sometimes employ communication strategies for keeping the conversation going for which the participants employ strategies to a) encourage and invite the other interlocutors to keep their turn in the conversation, b) to assist each other in completing or repairing the unfinished utterances, $c$ ) to let the problem pass (let-it-pass), and d) use of fillers to make the conversation go on. To achieve the function of maintaining the flow of 
conversation using fillers and self repetition are employed. Dornyie (1995) mentioned that use of fillers is a kind of time gaining or stalling strategies. He defined use of fillers as using filling words or gambits to fill pauses and to gain time to think (e.g., well, now let me see, as a matter of fact, you know). These strategies are functionally different from the other strategies (circumlocution, code witching or etc.) because they are not actually used to compensate for any linguistic deficiencies but rather to gain time and to keep the communication channel open at times of difficulty. It must be pointed out that communication maintenance strategies of this type have not been included in the most well-known taxonomies put forward by Tarone (1981), Færch and Kasper (1983), or Bialystok (1990). Several other researchers such as Canale \& Swain, (1980), Ellis, (1985), Haastrup \& Phillipson, (1983), however, have emphasized the significance of using fillers and hesitation devices as a conscious means to sustain communication in the face of difficulties. Hatch (1978, p. 434) also stated that learners should be told to use "whatever fillers they can to show the Native Speaker that they really are trying ... . the most important thing of all has to be "don't give up"'. Canale (1983, p.25 as cited in Dornyie and Thurrell, 1994, p.30) specifically listed the "use of pause fillers" among the communication strategies making up strategic competence. Haastrup and Phillipson (ibid) included in their taxonomy a set of strategies which they termed "strategies aimed at solving retrieval problems". According to the collected data of the study use of fillers are used more by teachers who teach in advanced level than teachers who teach in elementary level.

It has been observed that native speakers (NSs) adjust their speech in conversation with non-native speakers in various ways (Ferguson, 1971).This modified register has been termed 'foreigner talk' by Charles Ferguson (1971), and defined as "a register of simplified speech used by speakers of a language to outsiders who are felt to have very limited command of the language or no knowledge of it at all" (p.1). Therefore, foreigner talk is used more at elementary level (Ferguson 1971). One of the features of foreigner talk is using of high frequency vocabulary in speech (Ferguson 1971). According to this view, low frequency items are used more in advanced level and as Haastrup and Phillipson (1983) mentioned, in order to retrieve low frequency items or vocabularies, teachers use more use of fillers in this level, which is supported by the results.

The other subtype of communication strategy playing the role of maintaining the flow of conversation is self-repetition. Self-repetition occurs when the person repeats words, phrases, and gestures in the flow of conversation Although the reasons for self repetition may vary, the main one concerns planning for new material( Murata, 1994) . Natives (Perrin et al., 2003), bilinguals (Rieger, 2003), or non-natives produce self repetitions which have interactional functions targeting the maintenance of communication with the interlocutor.

As a fundamental aspect of language use, self repetition is common in every day interactions, and conversational partners draw on and deploy self repetition to support and sustain conversational discourse (Tannen, 2007). Teachers use self repetition in order to gain time for retrieving the item and by this way they maintain the flow of conversation and avoid abandonment of the message (Perrin et al., 2003)

As Dornyie and Scott (1997) argue, self repetition is the subtype of processing time pressure strategies. In these strategies the L2 speaker need for more time to process and plan L2 speech than would be naturally available in fluent communication (Dornyie and Scott, 1997). As mentioned before one of the features of foreigner talk is the use of high frequency items more than low frequency ones at elementary level, but in comparison with elementary level, in advanced level, low frequency items are used more by teachers (Ferguson, 1971). In order to gain time to retrieve low frequency items, teachers may use self-repetition and maintain the flow of conversation by this way.

Drawing upon the findings of this study, one may contend that foreign language classroom discourse is a rich source for investigating the nature, and functions of interaction. Even more intriguing can be the teacher-employed strategies that serve different communicative purposes. As revealed in this research, the teachers more than any other thing made an effort to maintain the flow of conversation. Such a significant load of strategy employment may indicate that the teachers would desire to continue with the verbal interaction as a source of motivation for classroom interaction and involvement in oral performance on the learners' part. Future research can aim at more delicate aspects of teacheremployed communication strategies to investigate issues of power, gender issues, the nature of topic, socio-cultural variables, fluency, accuracy and complexity of speech depending on particular strategy type and function. Furthermore, research on communication strategies and their functions can be extended further in scope to touch areas such as feedback, focus on form and task type so that teacher-initiated classroom interaction can be adequately characterized.

\section{References}

Abunawas, S. (2012). Communication Strategies Used by Jordanian EFL Learners. Canadian Social Science, 8(4), 178193.

Alptekin, C. ( 2002). Towards intercultural communicative competence in ELT. ELT Journal, 56 (1), 57-64.

Applegate, J.L. (1980).Adaptive communication in educational contexts: A study of teacher's communication strategies. Communication Education, 29,158-170.

Azian, A., Raof, A, Ismail, F and Hamzah, M. (2013). Communication strategies of non-native speaker novice science teachers in second language science classrooms, System 41, 283-297.

Bialystok, E. (1990). Communication Strategies: A Psychological Analysis of Second Language Use. Oxford: Basil Blackwell. 
Chen, S. Q. (1990). A study of communication strategies in interlanguage production by Chinese EFL learners. Language Learning, 40, 155-187.

Chin, C. (2006). Classroom interaction in science: teacher questioning and feedback to students' responses. International Journal of Science Education, 28 (11), 1315-1346.

Cullen, R. (2002). Supportive teacher talk: the importance of the F-move. ELT Journal, 56, 117-127.

Davies, A., (2002). The social component of language teacher education. In: Trappes-Lomax, H., Ferguson, G. (Eds.), Language in Language Teacher Education (pp.137-162) John Benjamins Publishing Company, Amsterdam

Dong, Y. (2010). Chinese Learners' Communication Strategies Research: a Case Study at Shandong Jiaotong University. Cross-Cultural Communication, 6(1), 56-81.

Dornyei, Z., \& Scott, M. L. (1997). Communication strategies in a second language definitions and taxonomies. Language Learning 47(1), 173-210.

Ellis, R. (1986). Understanding second language acquisition. Oxford: Oxford University Press.

Faerch, C., \& Kasper, G. (1983). Plans and Strategies in Foreign Language Communication. In Faerch \& Kasper (Eds.), Strategies in Interlanguage Communication (pp. 20-60). London: Longman.

Faucette, P. (2001). A pedagogical perspective on communication strategies: Benefits of training and an analysis of English language teaching materials. Second Language Studies, 19(2), 1-40

Ferguson, G. ( 2003). Classroom code-switching in post-colonial contexts: functions, attitudes, and policies. AILA Rev. $16,38-51$.

Hsieh, C. (1998). The relationship between anxiety and the use of communication strategies in L2 context. Unpublished MA Thesis, National Normal Taiwan University. Taiwan.

Hoekje, B. and Williams. J. (1992). Communicative competence and the dilemma of international teaching assistant education. TESOL Quarterly 26, 243-269

Jackson, J. (2002). Reticence in second language case discussions: Anxiety and aspirations. System, 30, 65-84

Jamshidnejad, A. (2011).Developing accuracy by using oral communication strategies in EFL interactions. Journal of Language Teaching and Research, 2(3), 350-536

Lam, W. (2010).Implementing communication instruction in the ESL oral classroom. What do low proficiency learners tell us. TESL Canada Journal,27(2), 11-30.

Liao, C.C., \& Bresnahan, M. I. (1996). A contrastive pragmatic study on American English and Mandarin refusal strategies. Language Sciences, 18, 703-727.

Littlemore,J.(2003). The communicative effectiveness of different types of communication strategy. System 31, 331347.

Littlewood, W. (1984). Foreign and Second Language Learning. Cambridge. Cambridge University Press.

Maleki , A. (2007). Teachability of communication strategies: An Iranian experience. System 35, 583-594.

Marinova-Todd, S., Marshall, D.B., \& Snow, C. (2000). Three misconceptions about age and L2 learning. TESOL Quarterly, 34, 9-34.

Martin, P. (1999). Bilingual unpacking of monolingual texts in two primary classroom in Brunei Darussalam. Language Education, 13 (1), 35-38.

Marton, F, Tsui, A.B.M .( 2004). Classroom discourse and the space of learning. Lawrence Erlbaum, Mahwah N.J.

Mei, A. (2010).Use of communication strategies by Chinese EFL learners. Chinese Journal of Applied Linguistics, $33(3), 1-15$.

Murata, Kumiko, 1994. Intrusive or co-operative? A cross-cultural study of interruption. Journal of Pragmatics 21, $385-400$.

Nassaji, H., Wells, G. (2000). What's the use of triadic dialogue? An investigation of teacher-student interaction. Applied Linguistics, 21 (3), 376-406.

O’Malley, J.M., Chamot, A.U. (1990). Learning strategies in second language acquisition. Cambridge University Press, Cambridge.

Ogane, M. (1998). Teaching communication strategies. Retrieved Feb 15, 2005, from http://web28.epnet.com.ezproxy.tamu.edu:2048/resultlist.asp

Omar , H.,Embi,M. ,andYunes, M.(2012). Learners' Use of Communication Strategies in an Online Discussion via Facebook . Procedia - Social and Behavioral Sciences, 64, 535 - 544.

Paribakht, T. (1985). Strategic Competence and Language Proficiency. Applied Linguistics, 6, 132-146.

Perrin, Laurent, Deshaies, Denise, Paradis, Claude, (2003). Pragmatic functions of local diaphonic repetitions in conversation. Journal of Pragmatics 35, 1843-1860.

Rieger, Caroline L. ( 2003). Repetitions as self-repair strategies in English and German conversations. Journal of Pragmatics 35, 47-69. 
Taron, E., \& Yule, G. (1989). Focus on language learner. Oxford: Oxford University Press.

Tarone, E. (1980). Communication Strategies, Foreigner Talk, and Repair in Interlanguage. Language Learning, 30, 417-431.

Tarone, E. (1981). Some Thoughts on the Notion of Communication Strategy. TESOL Quarterly, 15 (3), 285-295.

Tarone, E. (1983). Some thoughts on the notion of 'communication strategy.' In C. Færch \& G. Kasper (Eds.), Strategies in interlanguage communication (pp. 61-74). London: Longman.

Tarone, E. (1984).Teaching strategic competence in the foreign language classroom. In S. Savignon \& M. Berns (Eds.), Initiatives in communicative language teaching (pp. 127-136). Reading, MA: Addison Wesley.

Tarone, E., \& Yule, G. (1987). Communication strategies in East-West interactions. In L. E. Smith (Ed.), Discourse across cultures: Strategies in world English (pp. 49-65). Hemel Hempstead, UK: Prentice Hall.

Tarone, E., \& Yule, G. (1989). Focus on the language learner. Oxford: Oxford University Press.

Teng, H. (2012). A study on the teachability of EFL communication strategies. Procedia - Social and Behavioral Sciences, 46, $3566-3570$.

Todd, R.W. (2005). In an aeroplane, yes, in an aeroplane: within-unit repetitions in classroom discourse. RELC Journal, $36(2), 189-209$.

Tuan, H. (2001). Is extroversion-introversion tendency a variable in the choice of strategies in communication? Proceedings of the eighteenth conference on English teaching and learning in the republic of china, 306-324.

Ustunel, E., Seedhouse, P. (2005). Why that, in that language, right now? Code-switching and pedagogical focus. International Journal of Applied Linguistics, 15 (3), 302-325.

Viano, M.M., Conejos, P.G. (1996). Communicative functions of repetition in classroom interaction. RESLA, 11, 129141.

Willems, G. (1987). Communication strategies and their significance in foreign language teaching. System, 15, 351-364.

Wood, J. (2011).Communicative language teaching (CLT) and communication strategies (CSs). Theory and practice. Retrieved on December 18.2011 from: http://library.nakanishi.ac.jp/kiyou/gendaikokusai (7)/08.pdf.

Ya-ni, Z. (2007).Communication strategies and foreign language learning.US-China Foreign Language, 5(4), 1-22.

Yule, G., \& Tarone, E. (1997). Investigating communication strategies in L2 reference: pros and cons. In Kasper, G., \& Kellerman, E. (Eds.), Communication strategies (pp. 17-30). London: Longman.

Zhang, W. (2005). The selection of communication strategies by Taiwanese EFL elementary school students with different English proficiency levels in information gap activities. Unpublished MA Thesis, National Taipei University of Education. 